METHODOLOGIC ISSUES

\title{
Measuring parent attributes and supervision behaviors relevant to child injury risk: examining the usefulness of questionnaire measures
}

\section{B A Morrongiello, K House}

Injury Prevention 2004;10:114-118. doi: 10.1136/ip.2003.003459

\begin{abstract}
Objective: This study aimed to identify self report questionnaire measures of parent attributes and behaviors that have relevance for understanding injury risk among children 2-5 years of age, and test a new Parent Supervision Attributes Profile Questionnaire (PSAPQ) that was developed to measure aspects of protectiveness and parent supervision.

Methods: Naturalistic observations were conducted of parents' supervision of children on playgrounds, with questionnaires subsequently completed by the parent to measure parent education, family income, parent personality attributes, attributes relevant to parent supervision, and beliefs about parents' control over the child's health status. These measures were then related to children's risk taking and injury history. Results: Visual supervision, auditory supervision, and physical proximity were highly intercorrelated, indicating that parents employed all types of behaviors in service of supervision, rather than relying predominantly on one type of supervisory behavior. Physical proximity was the only aspect of supervision behavior that served a protective function and related to children's risk taking behaviors: parents who remained close to their children had children who engaged in less risk taking. On questionnaires, parents who reported more conscientiousness, protectiveness, worry about safety, vigilance in supervision, confidence in their ability to keep their child safe, and belief in control over their child's health had children who showed less risk taking and/or experienced fewer injuries. The new PSAPQ measure was associated with specific aspects of supervision as well as children's risk taking and injury history.

Conclusions: This study reveals several parent attributes and behaviors with relevance for child injury risk that can be measured via self report questionnaires, including the new PSAPQ.
\end{abstract}

U nintentional injuries are a leading cause of death and hospitalization for children beyond 1 year of age. ${ }^{2}$ For young children, most injuries occur in and around the home when they are presumably in the care of someone who is supervising them (that is, overseeing their activities). ${ }^{3}$ Inadequate supervision has been cited as a contributing factor for child injury in a variety of studies. ${ }^{4-13}$ However, very few studies have directly examined the relationship between supervision and child injury risk. ${ }^{10}{ }^{14-17}$

One of the greatest challenges to studying relations between supervision and child injury is deciding on appropriate measures of supervision. Naturalistic observations are time consuming, draining of personnel resources, and can produce distortions in data to the extent those observed behave unnaturally when being studied. ${ }^{18}$ Questionnaire measures have proven reliable and valid for studying a variety of parenting behaviors. ${ }^{19}$ However, there have been no attempts to develop questionnaire measures of supervision or protectiveness that relate to child injury risk. The goal of the present study was to address this gap in knowledge by developing the Parent Supervision Attributes Profile Questionnaire (PSAPQ) and relating the findings from this questionnaire to observed supervision behaviors, children's risk taking, and to children's injury history. We also incorporated measures of other caregiver attributes we thought likely to relate to supervision and/or child injury risk, including personality attributes, and beliefs about the extent of control that parents have over their child's health status.

In developing the PSAPQ we adopted a broad conceptual approach to supervision (that is, caregiver's overseeing the activities of children), focusing not only on supervisory behaviors but also on parent beliefs and attitudes that were likely to relate to supervisory behaviors. We surveyed literature on the topic of supervision, including the child neglect, child injury, child development, and parenting literatures. ${ }^{20-23}$ We identified supervisory behaviors (for example, visual and auditory monitoring, physical proximity), as well as parenting attributes relevant to child safety (for example, protectiveness, worry about safety, vigilance about safety, confidence in ability to parent to keep child safe) and then developed questionnaire items to tap these attributes. Preliminary tests were conducted with parents to confirm the comprehensibility of individual items, and then with other professionals to confirm the content validity. In the present study, we sought to test the predictive or criterion related validity of the questionnaire by relating questionnaire findings to naturalistic observations of parent supervision, children's risk taking, and injury histories. ${ }^{24}$

There is considerable research documenting that underlying personality attributes contribute substantially to cross situational consistencies in how adults behave. ${ }^{25}$ However, only a single study could be found relating caregiver personality attributes to children's risk of injury. ${ }^{26}$ Specifically, parents high in neuroticism had children who experienced more injuries. In the present study we examined whether two personality attributes, conscientiousness (extent to which an individual is dutiful, plans ahead, organized, consistent in carrying out tasks, purposeful, determined, and strong willed with respect to achieving desired goals)

Abbreviations: BFI, Big Five Inventory; IBC, Injury Behavior Checklist; PHLOC, Parent Health Locus Of Control; PSAPQ, Parent Supervision Attributes Profile Questionnaire 
and neuroticism (extent to which an individual is anxious, impulsive, experiences depressive affect, shows readiness to experience anger, and is vulnerable to stress), related to supervision behaviors, children's risk taking, and/or child injury history.

Prior research indicates that many parents believe that childhood injuries are normative events and they do not judge themselves capable of preventing injuries to children. ${ }^{27} 28$ We reasoned that parents holding such beliefs might be less vigilant about injury risk than parents who believed in their ability to exercise control over their child's injury experiences. To address this hypothesis we included a questionnaire measure to tap parents' beliefs about the extent of control they have over their child's health and injury status.

\section{METHOD}

Participants were 48 parent-child dyads $(46 \%$ female children, 54\% male children; $71 \%$ mothers, $29 \%$ fathers) randomly selected from seven local parks that were strategically sampled from those parks available in order to ensure considerable variation in the education and socioeconomic status of participants. For education level: 55\% completed some or graduated high school, $24 \%$ completed some or graduated university, $7 \%$ completed some graduate studies, and the remaining chose not to answer the question. For annual family income: $2 \%$ reported less than $\$ 20000,8 \%$ reported between $\$ 20000$ and $\$ 39999,15 \%$ reported between $\$ 40000$ and \$59 999, 29\% reported between $\$ 60000$ and $\$ 79$ 999; $10 \%$ reported incomes over $\$ 80000$, and the remainder chose not to answer the question. The only constraint on selecting a dyad was that the child had to appear to be between 2 and 5 years of age ( $\mathrm{n}=30$ children were $2-3$ years, $n=18$ children were $4-5$ years) and the parent had to be the sole supervisor.

Two types of measures were taken, observational measures and questionnaire measures. Based on a pilot study, a 20 minute observation period was selected. Parent-child dyads were unobtrusively observed, with measures coded after every two minute period (a vibrating alarm watch tracked two minute periods). Subsequently, parents were approached, asked to confirm the age of their child, and asked to complete questionnaires, with $\$ 10$ paid for participating. Refusal rate was $15 \%$.

\section{Observational measures}

Parent supervision comprised five behaviors that were coded at the end of each two minute period: visual supervision ( 3 = watching child continuously, $2=$ intermittently, $1=$ not at all $)$, auditory supervision $(3=$ able to hear the child continuously, $2=$ intermittently, $1=$ not at all), physical proximity $(5=$ constant physical contact with child, $4=$ intermittent physical contact, $3=$ constantly within arm's length reach, 2 = intermittently within reach, $\mathrm{l}=$ beyond reach of the child), parent distraction $(5=$ parent is completely focused on child, $4=$ parent is mostly focused on child with occasional distractions or interruptions, 3 = equal time is spent with distractions as attending to the child, $2=$ more time on distractions than attending to child, 1 = all the parent's time is spent on distraction activities), and parent engagement with child $(4=$ all the parent's time was spent actively playing with child, 3 occasional participant in child's activities, $2=$ parent was not participating in the child's activities but was engaged nonetheless, for example, smiled at child's activities, $1=$ completely uninvolved and inattentive to the child's play). Collapsing scores across the 10 two minute periods provided a total supervision score for each behavior.
Children's risk taking was measured by keeping a running total of the number of injury risk activities (that is, engaging in an activity that could lead to injury and/or demonstrated inappropriate use of playground equipment in a way that could lead to injury; for example, jumping off a moving swing; standing as one came down the slide) during each two minute period. Collapsing scores across the 10 two minute periods provided a total risk taking score.

Reliability estimates were computed for each behavior and exceeded 0.80 ( $\kappa$ statistic). Coders completed their observations independently (that is, from different locations within the park). Only data from the designated "primary" coder (randomly determined) were included in the analyses.

\section{Questionnaire measures}

Questionnaires were distributed to the parent in random order. The Family Information Questionnaire, which was developed by the first author, provided information about family income level and education level. The Injury History Questionnaire, which was developed by the first author, provided several different measures of the child's injury history, including medically attended injuries and an index of the frequency with which the child had sustained 17 different types of non-minor injuries (for example, fall down stairs or from a substantial height, crushing injury) since birth; non-minor injury was defined as tissue damage (for example, burn, bump, cut) that lasted for longer than one day. Prior research indicates that mothers accurately recollect child injury information for more serious injuries. ${ }^{29}$ Because of the young ages of the children we reasoned there might be too few medically attended injuries, thereby constraining our ability to identify significant relations between injuries and our measures. Hence, we also included a measure of nonminor injuries.

The Injury Behavior Checklist (IBC) provides a standardized measure of the child's typical level of risk taking. ${ }^{30}$ The parent is asked to rate the occurrence of 24 risky activities (for example, jumps down stairs). Higher scores indicate greater frequency of risk taking behaviors. The Parent Supervision Attributes Profile Questionnaire (PSAPQ), developed by the authors, is an evolving measure that seeks to identify aspects of supervision that relate to child injury risk. In the current version of the questionnaire there are four subscales that show adequate internal consistency, including: protectiveness (21 items, $\alpha=0.70$; for example, I make my child keep away from anything that could be dangerous), worry about safety (10 items, $\alpha=0.69$; for example, I spend much of my time worrying that he/she will get hurt), vigilance in supervision (11 items, $\alpha=0.68$; for example, I keep an eye on my child's face to see if he/she needs my help), and confidence in his/her ability to keep his/her son/daughter safe (eight items, $\alpha=0.65$; for example, I feel confident I know what my child can do). In addition, parents completed the Fate subscale from the Parent Health Locus Of Control (PHLOC) which provides an index of the extent to which parents believe that the health and injury status of their child is predominantly a matter of luck or fate (for example, Whether my child avoids injury is mostly a matter of luck). ${ }^{31}$ Parents also completed two subscales, neuroticism and conscientiousness, from a standardized personality measure, the Big Five Inventory (BFI). ${ }^{32}$

\section{RESULTS}

Table 1 shows the means and standard deviation scores obtained for all measures. Tables 2 and 3 show the intercorrelations between different measures.

As shown in table 2, visual, auditory, and physical supervision measures were highly intercorrelated. Parents seemed to have certain levels of supervision with which they were comfortable, and this was reflected in various indices of 
Table 1 Mean (SD) for the parent and child measures

\begin{tabular}{lcl}
\hline Measure & Mean (SD) & Possible range \\
\hline Parent & $2.59(0.65)$ & $1-5$ \\
Neuroticism (BFI) & $4.17(0.44)$ & $1-5$ \\
Conscientiousness (BFI) & $68.65(7.30)$ & $0-105$ \\
Protectiveness (PSAPQ) & $22.63(4.44)$ & $0-50$ \\
Worry (PSAPQ) & $37.62(4.55)$ & $0-55$ \\
Vigilance (PSAPQ) & $29.65(4.57)$ & $0-40$ \\
Confidence (PSAPQ) & $2.53(0.88)$ & $0-6$ \\
Fate beliefs (PHLOC) & $2.53(0.49)$ & $1-3$ \\
Visual supervision & $2.67(0.42)$ & $1-3$ \\
Auditory supervision & $2.12(0.66)$ & $1-5$ \\
Proximity to child & $4.24(0.84)$ & $1-5$ \\
Engagement with child & $1.91(0.85)$ & $1-5$ \\
Distraction & & \\
Child & & \\
Risk taking: & $23.06(11.99)$ & $0-96$ \\
IBC & $5.40(6.68)$ & $0+$ \\
$\quad$ Observed & $12.69(13.75)$ & $0+$ \\
Injury history: & $1.47(1.76)$ & $0+$ \\
$\quad$ Non-minor & & \\
Medically attended &
\end{tabular}

supervision behavior. Additionally, level of parental engagement and distraction were correlated with auditory supervision, visual supervision, and physical proximity. Hence, specific indices of different types of supervision behaviors were reflected also in two general measures of parental attention to the child.

Interestingly, proximity to the child (physical supervision) had the most positive relation to children's risk taking behavior during observations. As can be seen in table 2, greater physical proximity to the child was associated with less risk taking during the observations. Visual and auditory supervision, which typically occur at greater distance from the child, were not associated with decreases in children's risk taking during observations. Thus, although supervision behaviors were highly intercorrelated and tended to co-occur, physical proximity was the only supervision behavior associated with decreased risk taking in the immediate situation. Interestingly, none of the supervision behaviors related directly to either child injury history measure (see table 2). However, parent engagement with the child during our observations was negatively correlated with children's non-minor injuries. Parents who showed more engagement with their child, had children who had a history of having experienced fewer non-minor injuries.

As shown in table 2, there was no correlation between the observational measure of children's risk taking and the questionnaire measure of risk taking (IBC). This is not surprising given that the IBC taps children's risk taking in a broad range of situations, whereas our observation of risk taking was limited to a single environment, the playground. As expected, however, children who usually engage in risky activities also had a history of having experienced more injuries: IBC scores and history of non-minor injuries were highly positively correlated $(r=0.71, \mathrm{p}<0.001)$.

Table 3 provides correlations showing how questionnaire measures of parent attributes related to parent supervision, children's risk taking, and children's injury history; a composite measure of supervision was used because individual behaviors were so highly intercorrelated. As can be seen, neuroticism did not relate to parent supervision, children's risk taking or their injury risk. However, parents high on conscientiousness had children who usually engaged in less risk taking (IBC) and who had a history of fewer non-minor injuries.

Several subscales of the PSAPQ related to supervision, children's risk taking, and child injury history (see table 3). Specifically, parents who scored high either in protectiveness or worry about their child's safety had children who had a history of fewer non-minor injuries. That these two subscales did not relate to supervision behavior may indicate that parents use non-supervision strategies to protect their child and act on their worry about their child's safety. In contrast, subscales that tapped vigilance in supervision and confidence in a parent's ability to keep their child safe both related directly to supervision behaviors. Parents who scored high in vigilance showed closer supervision during our observations, and they also had children with a history of fewer non-minor injuries. Parents who had a high degree of confidence in their ability to keep their child safe showed closer supervision during our observations, and also had children who typically engaged in less risk taking and experienced fewer injuries. Overall, the PSAPQ demonstrated good convergent validity with related constructs in this initial test, with differential subscales relating to parent supervision, children's risk taking, and child injury risk.

Additional measures that tapped attributes of parents not in the PSAPQ also provided important insights into children's

Table 2 Intercorrelations among measures of supervision, children's risk taking, and injury history

\begin{tabular}{|c|c|c|c|c|c|c|c|c|c|}
\hline Measure & $\begin{array}{l}\text { Visual } \\
\text { supervision }\end{array}$ & $\begin{array}{l}\text { Auditory } \\
\text { supervision }\end{array}$ & $\begin{array}{l}\text { Physical } \\
\text { supervision } \\
\text { (proximity) }\end{array}$ & $\begin{array}{l}\text { Engagement } \\
\text { with child }\end{array}$ & Distraction & $\begin{array}{l}\text { Observed risk } \\
\text { taking }\end{array}$ & $\mathrm{IBC} \dagger$ & $\begin{array}{l}\text { Non-minor } \\
\text { injuries }\end{array}$ & $\begin{array}{l}\text { Medical } \\
\text { attended } \\
\text { injuries }\end{array}$ \\
\hline $\begin{array}{l}\text { Visual } \\
\text { supervision }\end{array}$ & - & - & - & - & - & - & - & - & - \\
\hline $\begin{array}{l}\text { Auditory } \\
\text { supervision }\end{array}$ & $0.74^{* *}$ & - & - & - & - & - & - & - & - \\
\hline $\begin{array}{l}\text { Physical } \\
\text { supervision } \\
\text { (proximity) }\end{array}$ & $0.31^{*}$ & $0.27^{*}$ & - & - & - & - & - & - & - \\
\hline $\begin{array}{l}\text { Engagement } \\
\text { with child }\end{array}$ & $0.69^{* *}$ & $0.48^{* *}$ & $0.57^{* *}$ & - & - & - & - & - & - \\
\hline Distraction & $-0.93^{* *}$ & $-0.61^{* *}$ & $-0.48^{* *}$ & $-0.75^{\star *}$ & - & - & - & - & - \\
\hline $\begin{array}{l}\text { Observed } \\
\text { risk taking }\end{array}$ & -0.15 & -0.14 & $-0.31^{*}$ & -0.20 & 0.13 & - & - & - & - \\
\hline IBC & -0.11 & -0.19 & -0.06 & -0.11 & -0.02 & 0.02 & - & - & - \\
\hline $\begin{array}{l}\text { Non-minor } \\
\text { injuries }\end{array}$ & 0.02 & -0.03 & 0.16 & $-0.31^{*}$ & -0.08 & 0.17 & $0.71^{\text {** }}$ & - & - \\
\hline $\begin{array}{l}\text { Medically } \\
\text { attended } \\
\text { injuries }\end{array}$ & -0.15 & 0.09 & -0.08 & -0.08 & 0.11 & 0 & 0.03 & -0.09 & - \\
\hline
\end{tabular}

†IBC, typical level of risk taking reported on IBC. ${ }^{*} \mathrm{p}<0.05 ;{ }^{* *} \mathrm{p}<0.01$. 
Table 3 Correlations showing how parent attributes relate to supervision (composite of visual supervision, auditory supervision and physical proximity scores), children's risk taking (IBC questionnaire, observed), and children's injury history (non-minor, medically attended)

\begin{tabular}{|c|c|c|c|c|c|c|c|}
\hline \multirow[b]{2}{*}{ Measure } & \multicolumn{7}{|c|}{ Parent attribute } \\
\hline & $\begin{array}{l}\text { Neuroticism } \\
\text { (BFI) }\end{array}$ & $\begin{array}{l}\text { Conscientiousness } \\
\text { (BFI) }\end{array}$ & $\begin{array}{l}\text { Protectiveness of } \\
\text { child (PSAPQ) }\end{array}$ & $\begin{array}{l}\text { Worry about } \\
\text { child's safety } \\
\text { (PSAPQ) }\end{array}$ & $\begin{array}{l}\text { Vigilance in } \\
\text { supervision } \\
\text { (PSAPQ) }\end{array}$ & $\begin{array}{l}\text { Confidence in } \\
\text { ability to keep } \\
\text { child safe (PSAPQ) }\end{array}$ & $\begin{array}{l}\text { Belief that child's } \\
\text { health mostly } \\
\text { due to fate } \\
\text { (PHLOC) }\end{array}$ \\
\hline $\begin{array}{l}\text { Supervision composite } \\
\text { Risk taking }\end{array}$ & -0.17 & -0.18 & 0.06 & 0.14 & $0.41^{* *}$ & $0.33^{*}$ & $-0.30^{*}$ \\
\hline IBC & 0.19 & $-0.31^{*}$ & -0.13 & -0.14 & -0.22 & $-0.34^{*}$ & 0.21 \\
\hline Observed & -0.18 & 0.04 & 0.19 & 0.25 & 0.10 & -0.11 & 0.26 \\
\hline Injury history & & & & & & & \\
\hline Non-minor & 0.05 & $-0.24^{*}$ & $-0.38^{* *}$ & $-0.40^{* *}$ & $-0.42^{* *}$ & $-0.27^{*}$ & $0.29^{*}$ \\
\hline Medically attended & -0.07 & -0.18 & -0.07 & -0.05 & -0.01 & -0.04 & 0.13 \\
\hline
\end{tabular}

injury risk. Parents who believed they had little control over their child's health and injury status showed decreased supervision of their children and had children with a history of more non-minor injuries (see last column in table 3). Hence, parents' beliefs about the extent to which their child's health status is attributable to luck had implications for both how they supervised and the number of injuries their child experienced.

\section{DISCUSSION}

This study addresses an important methodological issue regarding measurement approaches in studying how parents' attributes and behaviors, including supervision, relate to child injury risk. The findings from this study reveal a variety of parent attributes that can be measured reliably by questionnaires and that relate to parent supervision, children's risk taking, and/or children's injury histories.

Measures of parent personality attributes revealed the relevance of some attributes, and not others, for understanding child injury risk. Although parent neuroticism previously was found to be associated with increased risk of child injury, this was not the case in this sample. ${ }^{26}$ Parent conscientiousness, however, related to child injury risk. Parents high on conscientiousness had children who usually engaged in less risk taking and had a history of fewer injuries. Of course, what remains to be determined is whether this decreased risk taking is actually attributable to parenting practices of conscientious parents and, if it is, what it is that conscientious parents actually do in the course of their interactions with their children that result in decreased risk taking and child injury risk. Conscientiousness was not associated with increased supervision behaviors per se (see table 3). Possibly, these parents are somehow very effective in teaching their children about rules restricting injury risk behaviors or in structuring the environment to minimize risk taking, resulting in little need for close supervision in order to moderate children's risk behaviors. Suffice it to say, while it is unclear why children of conscientious parents engage in less risk taking and experience fewer injuries, the present findings indicate that parent conscientiousness serves a protective function for child injury, and this attribute can be reliably measured with a questionnaire.

Previous studies revealed that many parents attribute injuries to bad luck and do not believe in the preventability of child injuries. ${ }^{27}{ }^{28}$ The present study extends these findings to show that parents who believed that their child's health status was attributable largely to luck showed decreased supervision and had children who had experienced more

\section{Key points}

- This study demonstrates that questionnaire measures of parent attributes and behaviors can serve as important alternatives to more labor intensive, resource draining, observational measures of parenting behaviors.

- A number of parent attributes proved relevant for understanding child injury risk.

- The new Parent Supervision Attributes Profile Questionnaire (PSAPQ) related to parent supervision practices, children's risk taking, and children's injury history. Hence, this new measure holds promise for research that aims to link parent characteristics with child injury risk.

injuries. The fact that such beliefs can be easily measured with a questionnaire provides the means to further explore how parents' beliefs about fate relate to their injury prevention and safety promotion practices.

Finally, the results from this preliminary test of the newly developed PSAPQ suggest that this questionnaire holds promise for the future study of child injury risk. A number of subscales that tapped different parent attributes showed adequate internal consistency and related to parent supervision, children's risk taking, and/or children's injury history. Parents scoring high on either protectiveness, worry about safety, or vigilance in supervision, had children with a history of decreased injuries. Moreover, as one would expect, vigilance about safety and confidence in one's ability to keep one's child safe were both directly associated with the level of supervision shown by parents at the playground. In ongoing research, we are examining relations between self reports by parents on the PSAPQ and actual home supervision practices. Supervision behaviors we observed on the playground did not relate to children's injury history. However, this may reflect the fact that most injuries to young children happen in and around the home, rather than on playgrounds. Measuring home supervision, therefore, will likely have greater relevance for indexing child injury risk at these young ages.

\section{ACKNOWLEDGEMENTS}

This research was funded by a grant from the Social Sciences and Humanities Research Council of Canada. The authors extend their thanks to Natalie Johnson, Sophie Kiriakou, and Meghan McCourt for assistance with data collection; to Mike Corbett for assistance with data analysis; and to the parents for their willingness to participate in this study. 
Authors' affiliations

B A Morrongiello, K House, Psychology Department, University of Guelph, Guelph, Ontario, Canada

\section{REFERENCES}

1 Baker SP, O'Neil B, Ginsburg M. The injury fact book. New York: Oxford University Press, 1992.

2 Canadian Institute of Child Health. The health of Canada's children: a profile. 3rd Ed. Ottawa, Ontario: Canadian Institute of Child Health, 2000

3 Shannon A, Brashaw B, Lewis J, et al. Nonfatal childhood iniuries: a survey at the Children's Hospital of Eastern Ontario. CMAJ 1992;146:361-5.

4 Alwash R, McCarthy M. How do child accidents happen? Health Educ J 1987;46:169-71.

5 Garbarino J. Preventing childhood injury: developmental and mental health issues. Am J Orthopsychiatry 1988;58:25-51.

6 Garling A, Garling T. Mothers' supervision and perception of young children's risk of unintentional injury in the home. J Pediatr Psychol 1993;18:105-14.

7 Maleck M, Guyer B, Lescohier I. The epidemiology and prevention of child pedestrian injury. Accid Anal Prev 1990;22:301-13.

8 Morrongiello BA, Midgett C, Shields R. Don't run with scissors: young children's knowledge of home safety rules. J Pediatr Psychol 2001;26:105-15.

9 Morrongiello BA, Ondejko L, Littlejohn A. Understanding toddlers' in home injuries: I. context, correlates, and determinants. J Pediatr Psychol (in press).

10 Morrongiello BA, Ondejko L, Littlejohn A. Understanding toddlers' in home injuries: II. Examining parental strategies, and their efficacy, for moderating child injury risk. J Pediatr Psychol (in press).

11 Peterson L, Stern B. Family processes and child injury risk for injury. Behavior Research and Therapy 1997;35:179-90.

12 Rivara F, Bergman A, Drake C. Parental attitudes and practices towards children as pedestrians. Pediatrics 1989;84:1017-21

13 Wills K, Christoffel K, Lavigne J, et al. Patterns and correlates of supervision in child pedestrian injury. J Pediatr Psychol 1997;22:89-104.

14 Cataldo M, Finney J, Richman G, et al. Behavior of injured and uninjured children and their parents in a simulated hazardous setting. J Pediatr Psychol 1992;17:73-80.

15 Landen M, Bauer U, Kohn M. Inadequate supervision as a cause of injury deaths among young children in Alaska and Louisiana. Pediatrics $2003 ; 111: 328-31$
16 Morrongiello BA, Dawber T. Toddlers' and mothers' behaviors in an injuryrisk situation: implications for sex differences in childhood injuries. J Appl Dev Psychol 1998;19:625-39.

17 Morrongiello BA, Hogg K. Mothers' reactions to children misbehaving in ways that can lead to injury: Implications for sex differences in children's risk taking and injuries. Sex Roles (in press).

18 Johnson S, Bolstad O. Methodological issues in naturalistic observations: Some problems and solutions for field research. In: Hamerlynck L, Handy L, Mash E, eds. Behavior change: methodology, concepts, and practice. Champaign, IL: Research Press, 1973:7-67.

19 Kochanska A, Kuczynski L, Radke-Yarrow M. Correspondence between mothers' self-reported and observed child-rearing practices. Child Dev 1989:69:56-63

20 Coohey C. Defining and classifying supervisory neglect. Child Maltreatment (in press).

21 Iltus S. Parental ideologies in the home safety management of one to fouryear-old children [dissertation]. New York: City University of New York, 1994.

22 Mize J, Pettit G, Brown G. Mothers' supervision of their children's peer play. Developmental Psychology 1995;31:311-21.

23 Saluja G, Brenner R, Morrongiello BA, et al. The role of supervision in child injury risk: definition, conceptual, and measurement issues. Injury Control Safety Prom 2004;11:15-20.

24 DeVellis R. Scale development: theory and applications. 2nd Ed. San Diego, CA: Sage, 2003

25 Caspi A, Moffitt T. When do individual differences matter: a paradoxical theory of personality coherence. Psychological Inquiry 1993;4:247-71.

26 Davidson L, Hughes S, Richards M. Maternal personality and injury in children. Person Indiv Diff 1987;8:961-3.

27 Morrongiello BA, Dayler L. A community-based study of parents' knowledge, attitudes and beliefs related to childhood injuries. Can J Public Health 1996:87:383-8.

28 Eichelberger $\mathrm{M}$, Gotschall $\mathrm{C}$, Feely $\mathrm{H}$, et al. Parental attitudes and knowledge of child safety. Am J Dis Child 1990;144:714-20.

29 Pless C, Pless B. How well they remember: the accuracy of parent reports. Arch Pediatr Adolesc Med 1995:149:553-8.

30 Speltz M, Gonzales N, Quan L. Assessment of injury risk in young children: a preliminary study of the Injury Behavior Checklist. J Pediatr Psychol 1990;15:373-83

31 DeVellis R, DeVellis B, Blanchard L, et al. Development and validation of the Parent Health Locus of Control Scales. Health Educ Quart 1993:20:211-25.

32 John OP, Donahue EM, Kentle R. The big five inventory-versions 4a and 5 . Berkeley, CA: University of California, Institute for Personality Research, 1999. 